\title{
Patients with early-onset systemic juvenile idiopathic arthritis show more inflammation and worse outcome
}

\author{
R Russo ${ }^{*}$, M Katsicas \\ From 18th Pediatric Rheumatology European Society (PReS) Congress \\ Bruges, Belgium. 14-18 September 2011
}

\section{Background}

Systemic Juvenile Idiopathic Arthritis (SJIA) is heterogeneous in severity, course and outcome. Predictive factors for a poor outcome include persistent systemic features (fever, thrombocytosis) and younger age at onset.

\section{Aim}

To describe and analyze the disease features in patients with SJIA with very early onset and to compare them with those of patients with later onset.

\section{Methods}

Retrospective analysis of clinical data. Early-onset (EO) was defined as the start of SJIA prior to age 18 months. Variables included: demographic and clinical features at onset and outcome variables during disease course (pattern of course, presence of clinical joint damage [using the Juvenile Arthritis Damage Index or JADI], radiographic joint damage [erosions], destructive hip disease, disability [CHAQ > 0.5], growth retardation, development of macrophage activation syndrome [MAS], need for biologic agents, and death). Patients with EO were compared with patients with disease onset at age $\geq 18$ months. Chi square and Mann-Whitney tests were used for comparisons.

\section{Results}

192 patients (115 girls, 23 EO) followed between 1995 and 2010 were included. Age at onset was 12 (2-17) months in patients with EO, 72 (18-191) months in patients with non-EO. Delay in diagnosis (2 months) and duration of follow-up (10 vs 8 years) were similar in both groups. Eight patients (1 EO, 7 non-EO) died during the observation period. Patients with EO showed more frequently serositis $(\mathrm{p}=0.0003)$, hepatomegaly $(p=0.01)$, splenomegaly $(p=0.03)$, lower number of active joints $(\mathrm{p}=0.01), \mathrm{Hgb}(\mathrm{p}=0.02)$, and higher plt $(\mathrm{p}=0.04)$ at onset; more frequently MAS $(\mathrm{p}=0.0001)$, therapy with biologics $(\mathrm{p}=0.01)$, destructive hip disease $(\mathrm{p}=0.04)$, radiographic damage $(\mathrm{p}=0.01)$, growth retardation $(\mathrm{p}=0.05)$, disability $(\mathrm{p}=0.01)$, and higher JADI score $(\mathrm{p}=0.003)$.

\section{Conclusions}

Patients with SJIA starting before age 18 months show more systemic inflammatory features, and a poorer outcome than children with later disease onset. They may represent a distinct subset. This observation should prompt rheumatologists to initiate early aggressive therapy and close follow-up in this age group.

Published: 14 September 2011

doi:10.1186/1546-0096-9-S1-018

Cite this article as: Russo and Katsicas: Patients with early-onset systemic juvenile idiopathic arthritis show more inflammation and worse outcome. Pediatric Rheumatology 2011 9(Suppl 1):018.

\footnotetext{
* Correspondence: rrusso@garrahan.gov.ar

Service of Immunology \& Rheumatology, Hospital de Pediatría Prof. Dr. Juan P. Garrahan, Buenos Aires, Argentina
}

(c) 2011 Russo and Katsicas; licensee BioMed Central Ltd. This is an open access article distributed under the terms of the Creative 